\title{
Pseudoaneurysm of thoracic aorta presenting as inappropriate sinus tachycardia: a case report
}

\author{
Zahra Azizi $^{1,2}$, Pouria Alipour ${ }^{1,2}$, Maria Terricabras ${ }^{1}$ and Yaariv Khaykin ${ }^{1 *}$
}

\begin{abstract}
Background: Pseudoaneurysm of thoracic aorta as a complication of blunt trauma to the chest, can present with a variety of symptoms due to mass compression effect. Here we report the first pseudoaneurysm of thoracic aorta presenting with chronic cough and inappropriate sinus tachycardia. The purpose of this case report is to highlight pseudoaneurysm of thoracic aorta as a rare differential diagnosis for inappropriate sinus tachycardia.

Case presentation: Here we report a case of 29-year-old white woman, a nurse, with history of a motor vehicle accident. She initially presented to medical attention with inappropriate sinus tachycardia 2 years following the motor vehicle accident during her pregnancy. Six years later she underwent sinoatrial node modification after failing a number of medications. Days prior to the ablation she developed a mild cough which became constant within a week following ablation. A computed tomography scan of her chest performed as part of a workup revealed an outpouching of the inferomedial aspect of the aortic arch, which was compressing her left main bronchus. She underwent arch repair surgery and recovered without complications. Four years later she presented with significant symptomatic sinus bradycardia requiring pacemaker placement.

Conclusions: This is the first reported case of thoracic pseudoaneurysm of aorta presenting with inappropriate sinus tachycardia due to compression of the vagal nerve and cough as a result of the left main bronchus compressive effect; it highlights the importance of considering structural abnormalities in a differential diagnosis of inappropriate sinus tachycardia before any interventions.
\end{abstract}

Keywords: Inappropriate sinus tachycardia, Pseudoaneurysm of thoracic aorta, Chronic cough

\section{Introduction}

Pseudoaneurysm of thoracic aorta (PTA) can occur due to blunt trauma to the chest, cardiothoracic surgery, and connective tissue disorders $[1,2]$. This condition is usually asymptomatic and is incidentally identified on imaging studies. Depending on size and location of aneurysms, the symptoms if present may vary from dysphagia, hemoptysis, dyspnea, hoarseness, to recurrent pneumonitis $[2,3]$. There are few cases that report chronic cough due to compression of left main bronchus as a rare symptom of the aortic pseudoaneurysm [2-4]. Here we report the first case of PTA presenting with chronic cough and inappropriate sinus tachycardia (IST). The purpose of this

\footnotetext{
* Correspondence: y.khaykin@utoronto.ca

'Southlake Regional Health Centre, 602-581 Davis Drive, Newmarket, Ontario L3Y 2P6, Canada

Full list of author information is available at the end of the article
}

case report is to highlight PTA as a rare differential diagnosis for IST.

\section{Case presentation}

A 29-year-old white woman, a nurse, presented initially with sudden episodic palpitations in the absence of physical or emotional stress, which started during her pregnancy 6 years prior to visit and progressed to incessant rapid heart rates throughout the day. Her workup was negative for deep vein thrombosis (DVT), pulmonary embolism, thyroid dysfunction, and adrenal dysfunction. She had normal cardiac echocardiography. The results of a chest X-ray, ventilation-perfusion $(\mathrm{V} / \mathrm{Q})$ scan, as well as pulmonary function test (PFT) were normal. Her 24-hour Holter showed average heart rate of 118 beats per minute (bpm) with peak heart rate of 160 despite sotalol $80 \mathrm{mg}$ twice a day. Her past medical history was positive for 
tobacco smoking, psoriatic arthritis, tonsillectomy, and a motor vehicle accident (MVA) 2 year prior to the initial onset of tachycardia.

Since she had failed attempts at aggressive hydration, propranolol, atenolol, sotalol, and selective serotonin reuptake inhibitors (SSRIs), she was offered a sinoatrial (SA) node modification procedure using three-dimensional electroanatomic mapping. On the day of ablation, she presented with a mild cough. An electrophysiology study including programmed ventricular and atrial stimulation showed no evidence for dual atrioventricular (AV) nodal physiology and accessory pathway conduction and no evidence for any inducible ventricular or atrial arrhythmias. She had a heart rate of $110 \mathrm{bpm}$ at baseline that went up to $160 \mathrm{bpm}$ on $2 \mu \mathrm{g} /$ minute of isoproterenol and $180 \mathrm{bpm}$ on $4 \mu \mathrm{g} /$ minute of isoproterenol. An electroanatomic map of her right atrium and the SA node was constructed at rest and on isoproterenol (Fig. 1a, b). The course of the phrenic nerve was mapped using high output pacing. After sinus node (SN) modification, our patient's heart rate was 50-60 off isoproterenol with flat to inverted p-waves in the inferior leads (Fig. 2a, b). There was no visible injury to the phrenic nerve.

Following ablation, our patient developed symptoms of pericarditis, pleuritic pain radiating to her left shoulder, and worsening cough, particularly when lying down with some orthopnea. Her jugular venous pressure was normal. She was initially treated with diclofenac $50 \mathrm{mg}$ twice a day, Tylenol (acetaminophen), and levofloxacin $500 \mathrm{mg}$ daily. After 2 days, she presented with nausea, vomiting, loose stool, orthopnea, and worsening cough when lying down. A chest X-ray showed a small left pleural effusion and her electrocardiogram (ECG) was unchanged from the last ECG. Cardiac echocardiography remained normal with no evidence of pericardial effusion or other explanation for her symptoms. Doppler ultrasound (US) of her legs showed no DVT and her V/Q scan was negative for pulmonary embolism and chest fluoroscopy again confirmed normal phrenic nerve function. Her blood work was unremarkable.

A computed tomography (CT) scan of her chest showed an outpouching of the inferomedial aspect of the aortic arch $3.8 \times 3.9 \mathrm{~cm}$ in size which was compressing her left main bronchus. This was confirmed as a pseudoaneurysm by angiography (Fig. 3). She underwent resection and graft repair of the descending thoracic aorta with no complications. All her symptoms resolved after surgery and she returned to work. Four years following ablation she presented to our emergency room (ER) feeling weak and dizzy. She was found to have recurrent episodes of sinus arrest, with pauses up to 3 seconds followed by a nodal escape beat (Fig. 4a, b). She was not being treated with any medications known to suppress SN function at this time. She was admitted with diagnosis of sick sinus syndrome and underwent permanent pacemaker implantation.

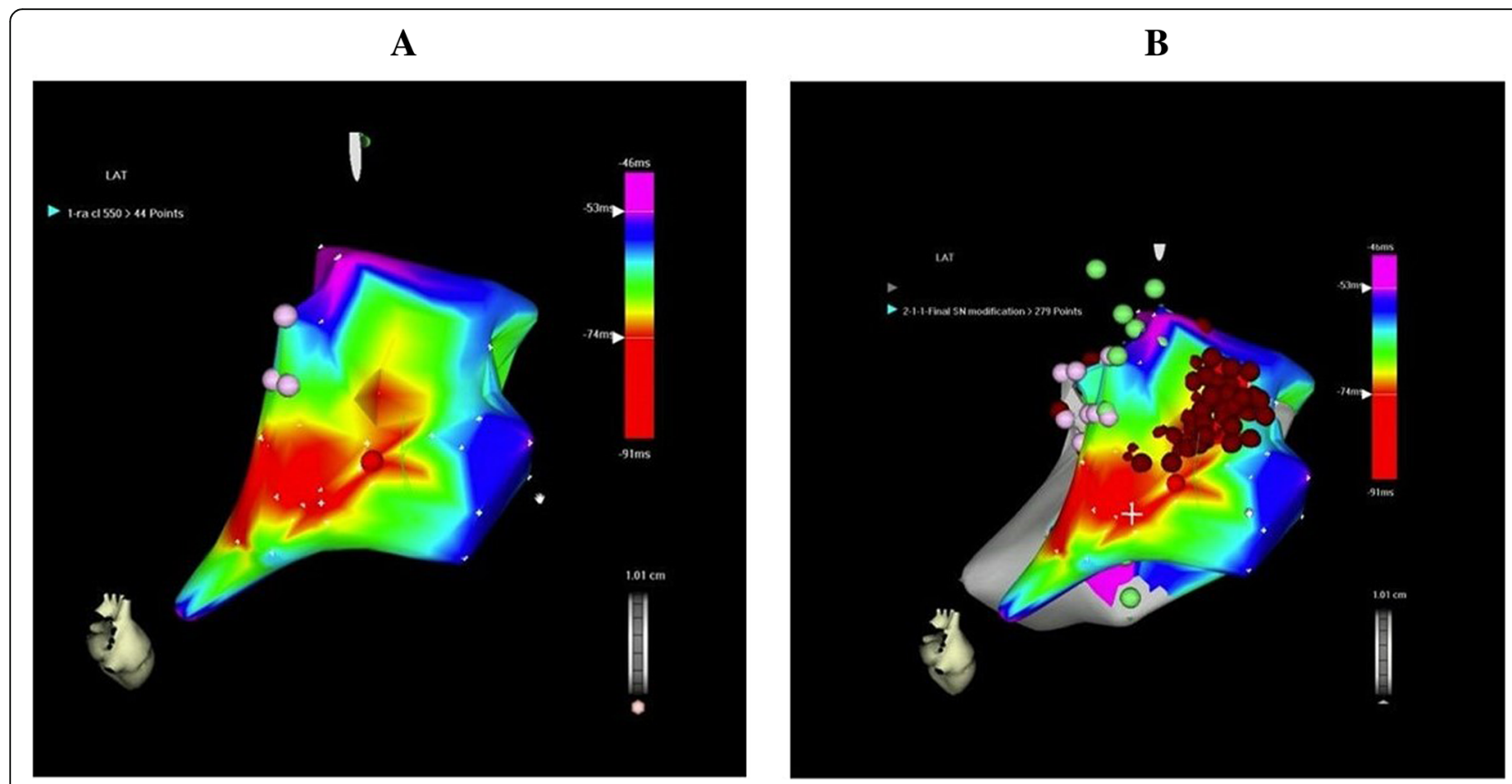

Fig. 1 Sinoatrial node is a long structure with slower more caudal portion of the node producing a flat or inverted p-wave in the inferior leads and faster more cranial portion of the node producing more upright p-waves. a Baseline electroanatomic map of sinus node map pre-isoproterenol at a baseline rate around 110 beats per minute. b Map following ablation: note that ablation was delivered at a more cranial portion of the sinus node 


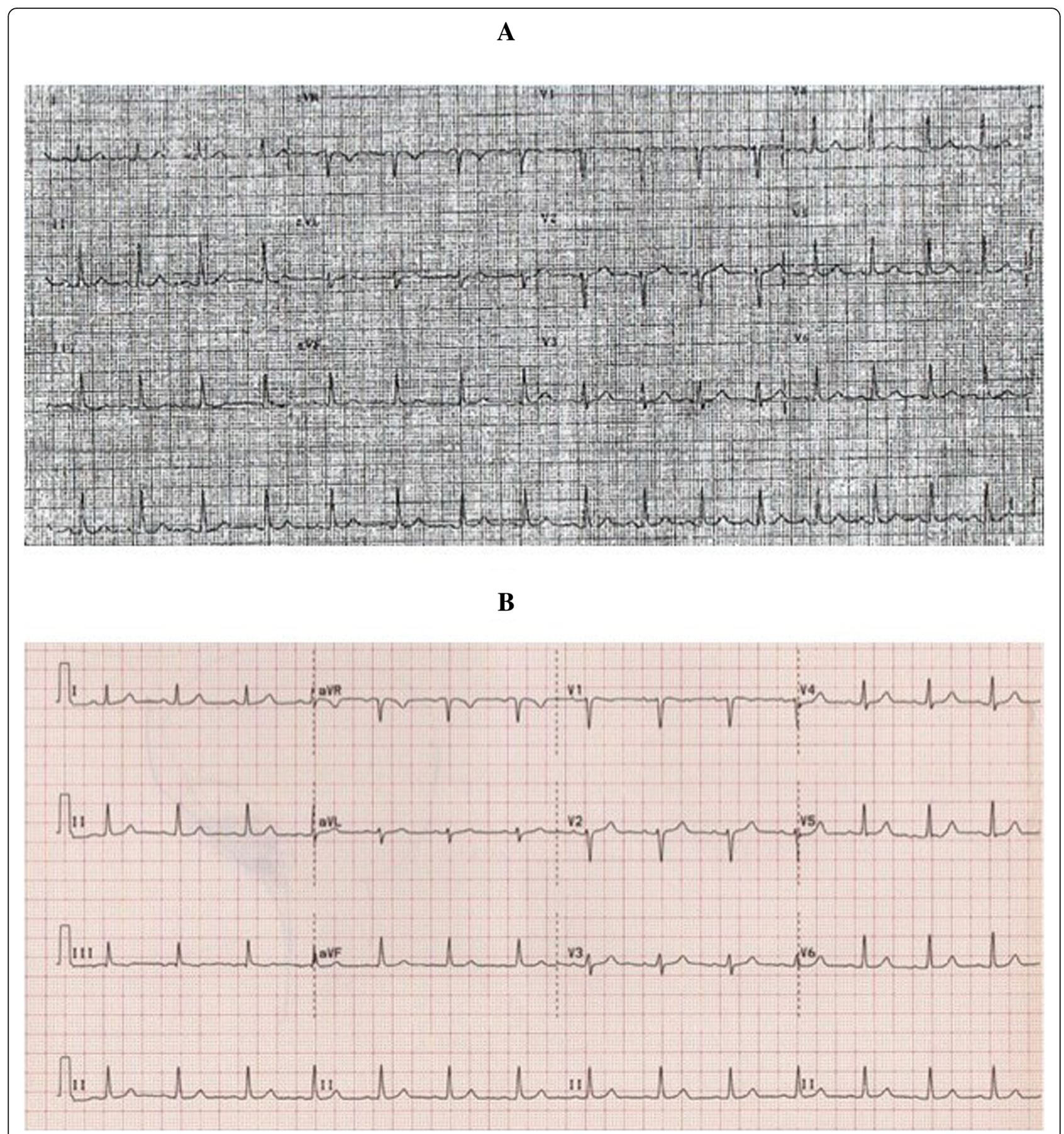

Fig. 2 a Patient baseline electrocardiogram before ablation. b Patient's electrocardiogram after ablation; notice flattening/inversion of the $p$-waves in the inferior leads

\section{Discussion}

Autonomic innervation of heart includes vagal (parasympathetic) and sympathetic fibers. IST is characterized by $\mathrm{SN}$-driven rhythm at a rate elevated over $100 \mathrm{bpm}$ or rapidly accelerating to over $100 \mathrm{bpm}$ without identifiable physiological or emotional stressors $[5,6]$. Potential mechanisms may include: an ectopic atrial focus close to the
SA node; increased sympathetic tone or decreased response to vagal stimulation due to reduced sensitivity of the muscarinic receptors [7]; depressed efferent vagal activation [8]; non-muscarinic, non-adrenergic, or vagally mediated mechanisms [9]; neurohormonal modulation [10]; hypothalamic paraventricular nucleus stimulation [11]; and intrinsic abnormality of the SA node $[5,6]$. 

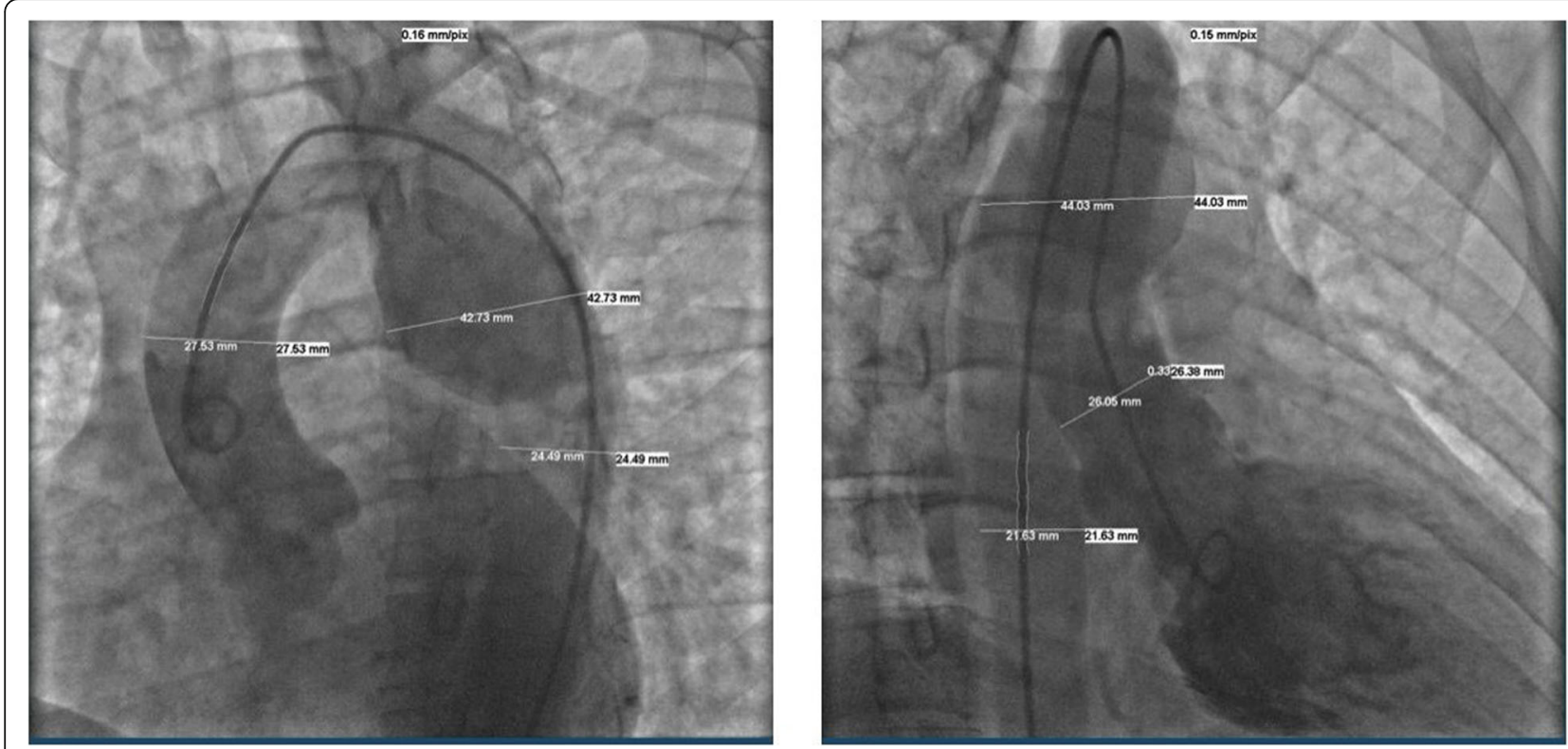

Fig. 3 Angiography of aortic arch confirming pseudoaneurysm of aorta

A variety of symptoms have been described to occur due to the local mass effect of a thoracic aortic aneurysm including cough as a result of tracheal or bronchial compression, and hoarseness due to stretching of the recurrent laryngeal nerve, dysphagia due to esophageal compression, and chest pain as an early sign of rupture or dissection $[1-4,12]$. This case shows a combination of cough and IST as presenting complaints related to the aortic pseudoaneurysm, probably the result of an earlier MVA. Changes in hemodynamics and soft tissues during pregnancy may have led to further dilatation of the aneurysm with impingement on the vagal nerve fibers constituting the cardiac plexus just in front of the tracheal bifurcation and, therefore, right under the expanding aneurysm [13]. Further enlargement of the lesion after ablation may have been related to the isoproterenol infusion used to increase the heart rate to $150 \mathrm{bpm}$ during mapping and ablation. This may have accelerated the process already under way, leading to tracheobronchial irritation by the enlarging aneurysm. Finally, 4 years after the aortic repair, and removal of the mass effect on the vagal nerve, our patient developed sick sinus syndrome which required a permanent pace maker possibly due to vagal re-innervation.

\section{Conclusion}

This is the first reported case of thoracic pseudoaneurysm of the aorta presenting with IST due to compression of

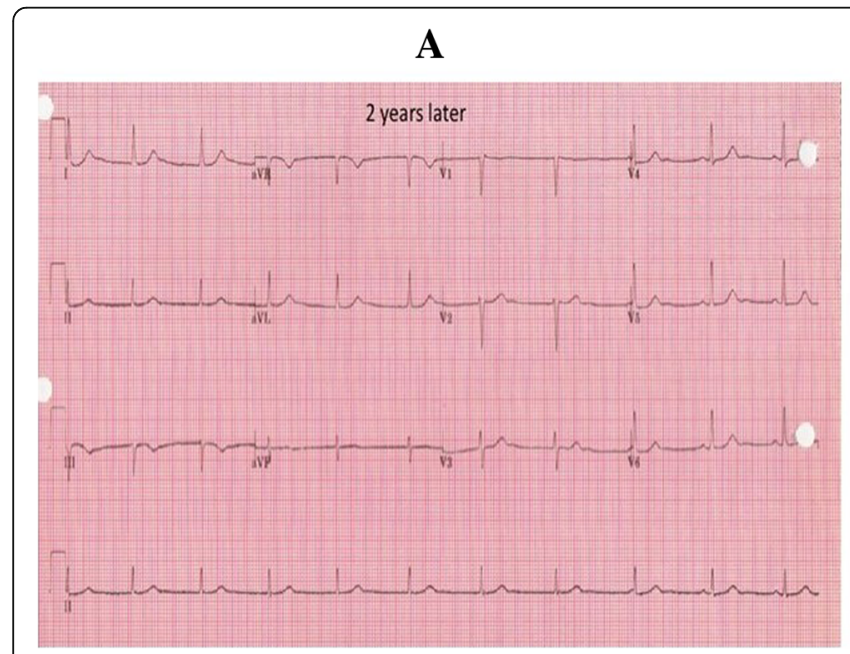

\section{B}
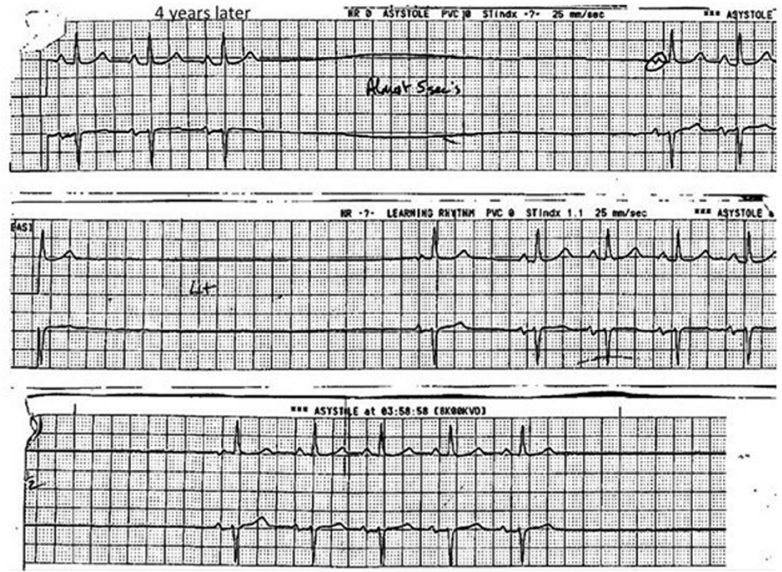

Fig. 4 Patient's electrocardiogram. a Two years after ablation. b Four years after ablation 
the vagal nerve and cough as a result of the left main bronchus compressive effect; it highlights the importance of considering structural abnormalities in a differential diagnosis of IST before any interventions.

\section{Key clinical message}

This is the first reported case of PTA presenting with IST due to compression of the vagal nerve and cough as a result of left main bronchus compression; it emphasizes the importance of considering structural abnormalities in a differential diagnosis of IST before any interventions.

\section{Acknowledgements}

None.

\section{Authors' contributions}

ZA, PA, MT, and YK: collaborated in drafting of the work and substantive revision; approved the submitted version, agreed both to be personally accountable for the author's own contributions and to ensure that questions related to the accuracy or integrity of any part of the work. PA: Drafting of the work, substantive revision, approved the submitted version, agreed both to be personally accountable for the author's own contributions and to ensure that questions related to the accuracy or integrity of any part of the work. MT: Electrophysiology fellow responsible for the patient. YK: The physician most responsible for the patient. All authors read and approved the final manuscript.

\section{Funding}

No funding was used for this study.

\section{Availability of data and materials}

Not applicable.

\section{Ethics approval and consent to participate}

This study has been approved by Southlake Regional Health Center's ethic board.

\section{Consent for publication}

Written informed consent was obtained from the patient for publication of this case report and any accompanying images. A copy of the written consent is available for review by the Editor-in-Chief of this journal.

\section{Competing interests}

The authors declare that they have no competing interests.

\section{Author details}

'Southlake Regional Health Centre, 602-581 Davis Drive, Newmarket, Ontario L3Y 2P6, Canada. ${ }^{2}$ York University Faculty of Heath, Toronto, Ontario, Canada.

Received: 9 April 2019 Accepted: 19 June 2019

Published online: 03 August 2019

\section{References}

1. Aranda J Jr, Tauth J, Henning RJ, O'Hara M. Pseudoaneurysm of the thoracic aorta presenting as purulent pericarditis and pericardial effusion. Catheter Cardiovasc Diagn. 1998;43(1):63-7.

2. Miller CP, Firoozan S, Woo EK, Apps A. Case Report: Chronic cough: a herald symptom of thoracic aortic aneurysm in a patient with a bicuspid aortic valve. BMJ Case Rep. 2014;2014 https://doi.org/10.1136/bcr-2014-205005

3. Giumelli C, Vazzana N, Bianchi A, Chesi G. Chronic cough revealing a giant thoraco-abdominal aortic aneurysm. Vasc Med. 2016;21(3):274-5.

4. Fatimi SH, Khan A, Shuja F, Javed MA, Ahmad U. Chronic cough secondary to post-traumatic pseudoaneurysm of the descending thoracic aorta. Heart, Lung Circ. 2008;17(1):59.

5. Morillo CA, Klein GJ, Thakur RK, Li H, Zardini M, Yee R. Mechanism of 'inappropriate' sinus tachycardia. Role of sympathovagal balance. Circulation. 1994;90(2):873-7.
6. Olshansky B, Sullivan RM. Inappropriate sinus tachycardia. J Am Coll Cardiol. 2013;61(8):793-801.

7. Dunstan $\mathrm{R}$, Jackson $\mathrm{D}$. The demonstration of a change in responsiveness of mice to physostigmine and atropine after withdrawal from long-term haloperidol pretreatment. J Neural Transm. 1977;40(3):181-9.

8. Hildreth CM, Padley JR, Pilowsky PM, Goodchild AK. Impaired serotonergic regulation of heart rate may underlie reduced baroreflex sensitivity in an animal model of depression. Am J Phys Heart Circ Phys. 2008;294(1):H474-H80

9. Prud'homme M-J, Houdeau E, Serghini R, Tillet Y, Schemann M, Rousseau JP. Small intensely fluorescent cells of the rat paracervical ganglion synthesize adrenaline, receive afferent innervation from postganglionic cholinergic neurones, and contain muscarinic receptors. Brain Res. 1999; 821(1):141-9.

10. Hill M, Wallick D, Mongeon L, Martin PJ, Levy MN. Vasoactive intestinal polypeptide antagonists attenuate vagally induced tachycardia in the anesthetized dog. Am J Phys Heart Circ Phys. 1995;269(4):H1467-H72.

11. Kawabe T, Chitravanshi VC, Nakamura T, Kawabe K, Sapru HN. Mechanism of heart rate responses elicited by chemical stimulation of the hypothalamic paraventricular nucleus in the rat. Brain Res. 2009;1248:115-26.

12. Yeo TC, Malouf JF, Oh JK, Seward JB. Clinical profile and outcome in 52 patients with cardiac pseudoaneurysm. Ann Intern Med. 1998;128(4): 299-305.

13. Coady MA, Adler F, Davila JJ, Gahtan V. Nonrecurrent laryngeal nerve during carotid artery surgery: case report and literature review. J Vasc Surg. 2000; 32(1):192-6.

\section{Publisher's Note}

Springer Nature remains neutral with regard to jurisdictional claims in published maps and institutional affiliations.

\section{Ready to submit your research? Choose BMC and benefit from:}

- fast, convenient online submission

- thorough peer review by experienced researchers in your field

- rapid publication on acceptance

- support for research data, including large and complex data types

- gold Open Access which fosters wider collaboration and increased citations

- maximum visibility for your research: over $100 \mathrm{M}$ website views per year

At BMC, research is always in progress.

Learn more biomedcentral.com/submissions 